\title{
The Successful Use of a Novel Microwave Device in the Treatment of a Plantar Wart
}

\author{
Ivan Robert Bristow ${ }^{a} \quad$ Christopher Webb ${ }^{b}$ \\ Michael Roger Ardern-Jones ${ }^{c, d}$ \\ ${ }^{a}$ Faculty of Health Sciences, University of Southampton, Southampton, UK; \\ ${ }^{\mathrm{b}}$ The Podiatry Centre, Portsmouth, UK; ${ }^{\mathrm{C}}$ Faculty of Medicine, University of Southampton, \\ Southampton, UK; ${ }^{d}$ Department of Dermatology, University Hospitals Southampton NHS \\ Foundation Trust, Southampton, UK
}

\section{Keywords}

Warts · Verrucae $\cdot$ Treatment $\cdot$ Infections $\cdot$ Microwave $\cdot$ Human papilloma virus

\begin{abstract}
Plantar warts, caused by the human papilloma virus (HPV), are a commonly encountered condition presenting in clinic. In adults, an array of various therapies exists, frequently with modest results particularly with plantar lesions. Microwaves have had limited uses for medical purposes. Recently a new portable microwave device has been approved for the treatment of skin lesions. Prior research has demonstrated immuno-stimulatory effects against HPV infection. We report the application of a novel portable medical microwave unit to treat a long-standing plantar wart which had failed to respond to other treatment modalities.
\end{abstract}

\section{Introduction}

Cutaneous warts are a common clinical problem estimated to affect between 7 and $12 \%$ of the population [1]. For many younger patients, natural resolution is a common feature, but in adults they often remain stubborn and refractory to treatment. As highlighted in re- 
cent guidelines, long-term persistence and failure to respond to therapy are more commonly features of cutaneous warts located on the plantar area of the foot [2]. In addition to the low success rate of common therapies such as salicylic acid and cryosurgery for warts in this location, these therapies cause local irritation and pain making their use unfavourable [2].

\section{Case Report}

A 41-year-old male with a stubborn, single plantar wart on his right styloid process which had been present for over a year and had failed to respond to treatment with cryosurgery (Fig. 1). The lesion was described as painful when standing. The lesion measured 10 by $10 \mathrm{~mm}$, and the patient rated the pain level as an 8 out of 10 (numeric rating scale) at the initial assessment. He had no significant past medical or medication history. Following a discussion with the patient about the various options available, the patient consented for treatment using microwave energy. After gentle reduction of the hyperkeratotic skin overlying the lesion, microwave energy was applied using the Swift S800 Microwave Device (Emblation Medical Ltd, Alloa, UK). Device settings were programmed to deliver $50 \mathrm{~J}(10 \mathrm{~W}$ for $5 \mathrm{~s}$ ). Microwaves were delivered without topical or local anaesthetic to the verruca through an applicator applied directly onto the surface of the lesion. After intervention, no dressing was required, and the patient was able to mobilise freely. After 3 weeks, the patient was reviewed. The treated area demonstrated large amounts of bruising (Fig. 2). Pain measurement was recorded as 2 out of 10 (NRS), corresponding to a 75\% improvement compared to pre-operative levels. Interestingly, the patient noted that pain had reduced almost immediately following the first microwave ablation. A second treatment of $50 \mathrm{~J}$ was administered to the same area under the same settings. Two weeks later, the lesion was almost completely resolved (Fig. 3) and pain score assessment was 0 out of 10 (NRS). At 6-month follow-up, the lesion remained fully resolved (Fig. 4).

\section{Discussion}

This case represents a report of successful treatment of a cutaneous wart using a portable microwave therapy device. The device was developed and subsequently "CE" marked as a medical device for the general indications "in the treatment and ablation of skin lesions." In this singular case presentation, the microwave device proved successful and creates a pathway for further research into the treatment of plantar warts. Microwaves are a type of nonionising radiation in the $300 \mathrm{MHz}$ to $300 \mathrm{GHz}$ wavelength range of the electro-magnetic spectrum. Application to the skin works on the principle of dielectric heating. Polar molecules, such as water, when exposed to microwave energy, rotate and attempt to align with the changing electro-magnetic field. At microwave frequencies, rapidly rotating molecules generate heat which is dissipated to the surrounding tissues and acts to rapidly elevate temperatures. To date, the medical applications of microwaves have been relatively limited and not widely explored. The technology has been successfully utilised intra-operatively to ablate large tumours $[3,4]$ but little work has focused on its applications in the treatment of skin lesions. The unit produces microwave energy within the $8 \mathrm{GHz}$ range from an internal generator, delivered through a cable into a ceramic cap, directly into the tissues to which it is applied. The applicator tip of the device is single use reducing the risk of cross-infection. The physical properties of microwaves potentially offer significant advantages over cryotherapy 
and laser modalities when used medically on the skin. Firstly, as microwaves travel through tissue in straight lines in alignment with the device tip, there is minimal lateral spread of heat, meaning minimal damage to surrounding tissue. Moreover, microwave energy is not dependent on tissue conductivity, and tissue effects can therefore be produced much more rapidly than with cryotherapy cooling. Compared to laser light, microwaves are not modified by chromophores, and therefore microwaves show a greater depth of penetration into the skin. At powers of up to $10 \mathrm{~W}$, a penetration of up to $3 \mathrm{~mm}$ can be expected. An additional advantage is that the procedure does not induce vapour, smoke or particulate debris, which is a common problem with high energy lasers, and has been reported to spread viral particles within the plume [5]. Additionally, the device causes no skin breakage at site of application (at this energy setting) and so did not require any post-operative dressing, allowing the patient continue normally activity. The benefits of a heat therapy over a cold treatment such as liquid nitrogen application can be seen as the wart virus, although stable in temperatures of $196^{\circ} \mathrm{C}$ is more sensitive to heating than cold.

Studies on the effects of heating normal and human papilloma virus (HPV)-infected tissue suggest that it may promote the induction of adaptive immunity [6-10]. Microwave damage to HPV in an in vitro study on genital warts was compared with that caused by treatment with a $\mathrm{CO}_{2}$ laser. The authors of the work concluded that microwaves were significantly more effective at denaturing HPV than the comparative device [11]. Preliminary studies of human skin explants exposed to low-level microwave energy suggested that increased danger signalling in keratinocytes, including induction of HSP70, may be the critical pathway for cutaneous wart resolution. Microwave-treated keratinocytes were able to induce dendritic cell activation (CD80, CD86, CD40) and enhancement of anti-HPV responses by CD8+ T cells $[12,13]$. This case study represents an exciting additional therapeutic option for treatment of recalcitrant cutaneous warts. We acknowledge the limitations of reporting a single case, and further work to address this in a randomised controlled trial setting is underway.

\section{Conclusion}

This work represents a single case study of a persistent and painful wart treated successfully using microwave energy applied directly to the lesion using a novel medical device. Further work is required to fully assess the effectiveness of this therapy.

\section{Statement of Ethics}

This case study was drawn from an ongoing project which has been granted full ethical approval from the Faculty of Health Sciences, University of Southampton. Full consent was obtained from the patient for use of this case study.

\section{Disclosure Statement}

I.R.B. is a consultant for Emblation Medical Limited. 


\section{Case Reports in Dermatology}

\begin{tabular}{l|l}
\hline Case Rep Dermatol 2017;9:102-107 \\
\hline DOI: 10.1159/000477377 & $\begin{array}{l}\text { C 2017 The Author(s). Published by S. Karger AG, Basel } \\
\text { www.karger.com/cde }\end{array}$ \\
\hline
\end{tabular}

Bristow et al.: The Successful Use of a Novel Microwave Device in the Treatment of a Plantar Wart

\section{References}

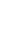

Lynch MD, Cliffe J, Morris-Jones R: Management of cutaneous viral warts. BMJ 2014;348:3339-3352.

Sterling JC, Gibbs S, Haque Hussain SS, Mohd Mustapa MF, Handfield-Jones SE: British Association of Dermatologists' guidelines for the management of cutaneous warts 2014. Br J Dermatol 2014;171:696712.

3 Wolf FJ, Grand DJ, Machan JT, Dipetrillo TA, Mayo-Smith WW, Dupuy DE: Microwave ablation of lung malignancies: effectiveness, CT findings, and safety in 50 patients. Radiology 2008;247:871-879.

-4 Matsukawa T, Yamashita Y, Arakawa A, Nishiharu T, Urata J, Murakami R, Takahashi M, Yoshimatsu S: Percutaneous microwave coagulation therapy in liver tumors. A 3-year experience. Acta Radiol 1997;38:410-415.

-5 Karsai S, Daschlein G: “Smoking guns”: Hazards generated by laser and electrocautery smoke. J Dtsch Dermatol Ges 2012;10:633-636.

6 Wang X, Gao XH, Li X, Hong Y, Qi R, Chen HD, Zhang L, Wei H: Local hyperthermia induces apoptosis of keratinocytes in both normal skin and condyloma acuminata via different pathways. Apoptosis 2009;14:721-728.

7 Zhu L-l, Gao X-H, Qi R, Hong Y, Li X, Wang X, McHepange UO, Zhang L, Wei H, Chen H-D: Local hyperthermia could induce antiviral activity by endogenous interferon-dependent pathway in condyloma acuminata. Antiviral Res 2010;88:187-192.

8 Ma Y, Huo W, Hong YX, Chen HD, Gao XH: Successful clearance of facial common warts by local hyperthermia: report of two cases. Dermatol Ther 2012;25:386-388.

Huo W, Di ZH, Xiao BH, Qi RQ, Weiland M, Gao XH: Clearance of genital warts in pregnant women by mild local hyperthermia: a pilot report. Dermatol Ther 2014;27:109-112.

10 Xinghua G, Hongduo C: Hyperthermia on skin immune system and its application in the treatment of HPV-infected skin diseases. Front Med 2014;12:9-13.

11 Li HX, Zhu W-Y, Xia M-Y: Detection with the polymerase chain reaction of human papillomavirus DNA in condylomata acuminata treated with $\mathrm{CO}_{2}$ laser and microwave. Int I Dermatol 1995;34:209-211.

12 Ardern-Jones M, Lee A, Chean LW, Holbrook D, Savelyeva N, Thomson P, Webb C, Polak ME, Bristow IR: Induction of antihuman papillomavirus immunity by microwave treatment of skin. Br J Dermatol 2016;175:151.

13 Bristow IR, Lim W, Lee A, Holbrook D, Savelyeva N, Thomson P, Webb C, Polak ME, Ardern-Jones MR: Microwave therapy for cutaneous human papilloma virus infection. Eur J Dermatol, accepted.

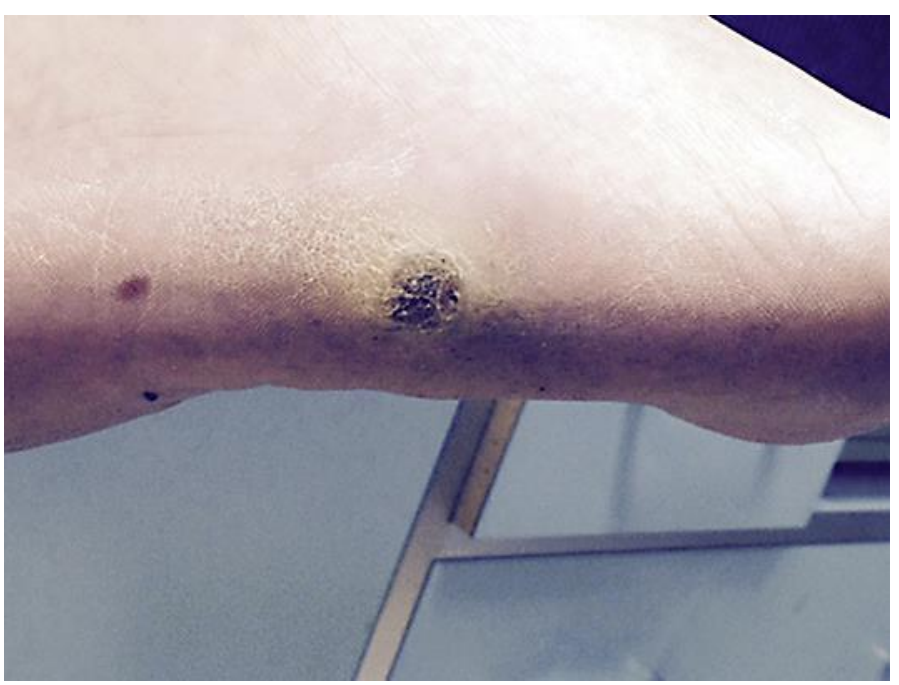

Fig. 1. Lesion at presentation $(10 \times 10 \mathrm{~mm})$. 


\section{Case Reports in Dermatology}

(C) 2017 The Author(s). Published by S. Karger AG, Basel www.karger.com/cde

Bristow et al: The Successful Use of a Novel Microwave Device in the Treatment of a Plantar Wart

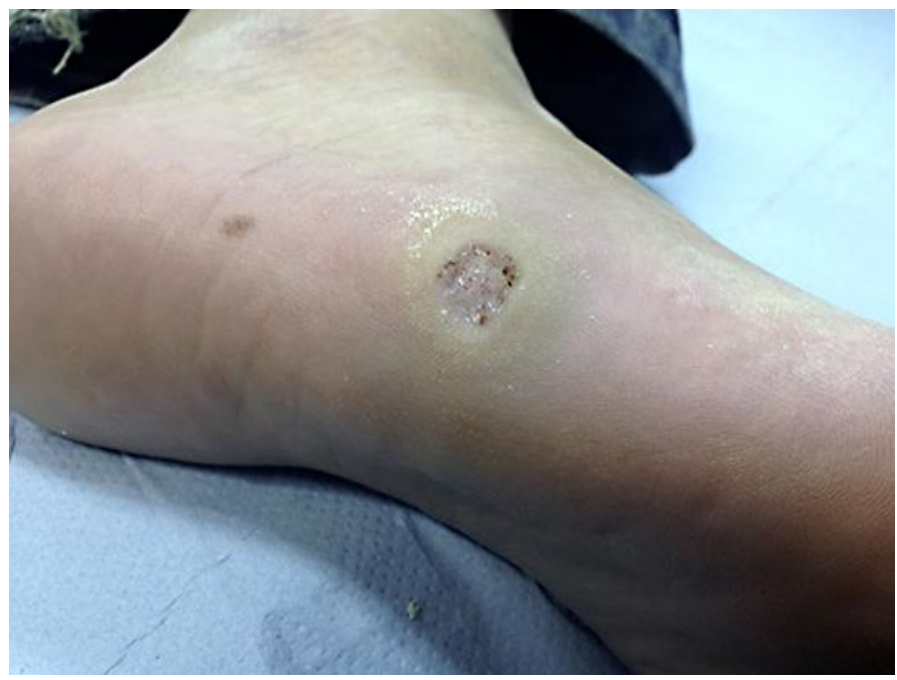

Fig. 2. Lesion at 3 weeks after treatment.

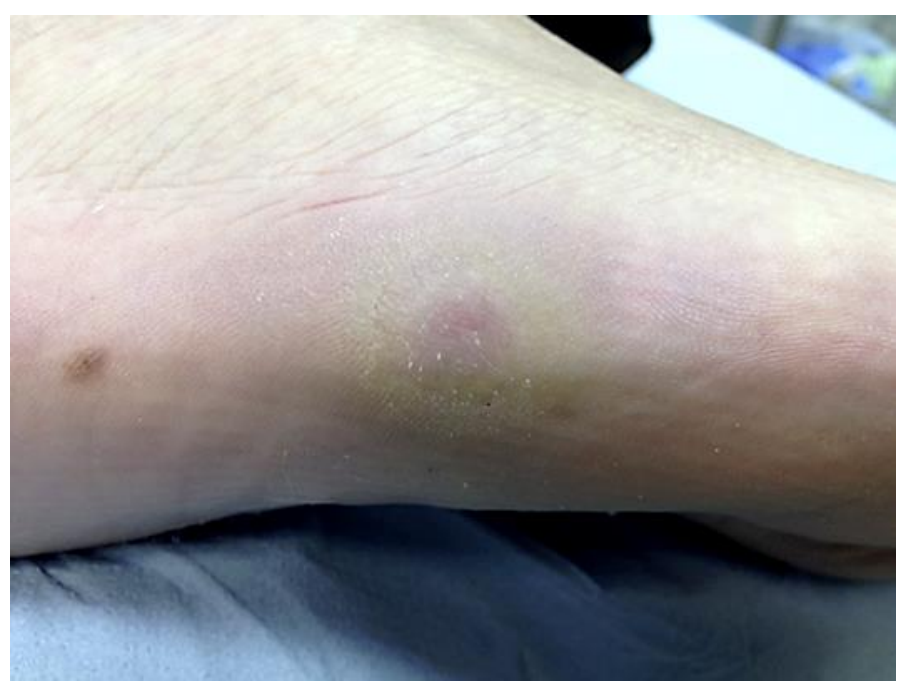

Fig. 3. Lesion at 5 weeks following 2 treatments. 


\section{Case Reports in \\ Dermatology}

Case Rep Dermatol 2017;9:102-107

DOI: $10.1159 / 000477377$

C 2017 The Author(s). Published by S. Karger AG, Basel www.karger.com/cde

Bristow et al.: The Successful Use of a Novel Microwave Device in the Treatment of a Plantar Wart

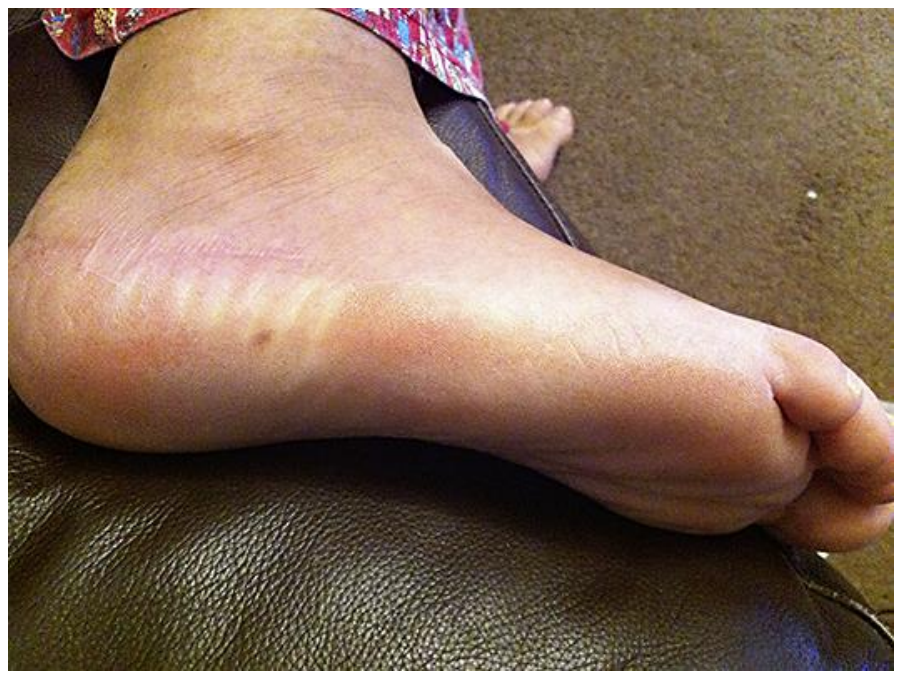

Fig. 4. Lesion resolved at second visit post-operatively. 